\title{
Recent Advancements in the Morphologic Description of Cloacal Development Have Implications for Oncologic Resection of Tailgut Cysts
}

\author{
K Nicoll* \\ Surgical Department, Ninewells Hospital and Medical School, UK
}

Submission: April 03, 2020; Published: April 08, 2020

*Corresponding author: K Nicoll, Surgical Department, Speciality Registrar General Surgery, Ninewells Hospital and Medical School, Ward 7, Dundee, Scotland, DD2 1SG, UK

\begin{abstract}
Tailgut cysts are rare para-rectal lesions thought to arise from incomplete involution of the tailgut during ontogenesis. They commonly present to gastroenterologists with tenesmus, extra-luminal compression, disturbance of bowel habit or rectal bleeding and carry significant threat of malignant transformation; particularly adenocarcinoma.

Guidelines on treatment of colonic adenocarcinoma are well established internationally. However, there are no guidelines on tailgut cyst management which can make onward referral for consideration of resection challenging. This problem is compounded by the inaccessibility of these cysts to visualisation or biopsy by endoscopy.

A significant barrier to consensus on the approach to these lesions is that there is presently scant explanation on their morphogenesis. Ontogenesis is the guiding principle in resection of colonic adenocarcinoma, where the lesions are resected en bolc with their embryonic mesentery, which contains their draining lymphatics. Recent developments in the description of the embryology of the anorectal region have resolved old morphogenic controversies and point the way to a rational approach to resection of tail gut cysts.

Keywords: Tailgut Cysts; Oncologic; Resection; Adenocarcinoma; Embryology; Morphogenesis; Zygosis; Cancer; Pararectal

Abbreviations: HRES: High Resolution Episcopic Microscopy; SEM: Scattering Electron Microscopy; TME: Total Mesorectal Excision
\end{abstract}

\section{Opinion}

Recent systematic evaluation of tailgut cysts cases has suggested that more than a quarter of these undergo malignant transformation [1]. Technique in modern colorectal cancer resections is built on the belief that total mesocolonic and mesorectal excision (TME) gives the best chance of curative resection. The basis for this practice is the orthodoxy that the large bowel and its mesentery constitute a single embryonic entity, intact but veiled by zygosis in the adult [2]. In the adult colonic and rectal lymphatics respect embryologic boundaries and can be clearly surgically delineated from the retroperitoneum. However, while they are presumed to represent tailgut remnants, there is no precise description of the morphogenesis of tailgut cysts. This makes it impossible to form a rational approach to their resection with oncologic margins, a concerning problem given their rate of malignant transformation.

Tailgut cysts are typically found anterior to the sacrum, in close association with the mesorectum $[1,3]$. In contrast, the embryonic tailgut is described as extending caudally from the cloaca or nascent anus. This casts doubt on the claim that peri-rectal cysts in the infant and adult actually represent tailgut cysts. How can their putative origins and their adult anatomy be married?

While classical morphological descriptions have a phylogenetic dimension, in gut rotation this is often lacking. The empirical success of the TME approach notwithstanding, direct embryological evidence for enteric rotational processes is poor $[4,5]$. The description of visceral rotation prevalent in textbooks represents an expedient construct which was largely arrived at a priori based on the 'malrotations' observed in infants. Description of the ontogenesis of tailgut cysts specifically has been further retarded by controversy over the means of division of the cloaca. In particular, the classical cloacal septation models of Retterer \& Tourneux [6,7]; which were based on concrescence of infolding of the cloaca or a descending curtain of mesenchyme respectively. These models have not withstood contemporary interrogation by three dimensional techniques; specifically scattering electron 
microscopy (SEM) [8] or high resolution episcopic microscopy (HRES) [9] in a murine model. The classical descriptions, and disagreement between them, seem to arise from artefacts caused by the plane through which histological sections were taken.

A newer model is emerging [8-10] which views the septation of the cloaca as largely passive and contributed to mostly by unfolding of the caudal embryonic curve and distortion of the cloaca by marked growth of the genital tubercle (Figure 1). There is also no evidence from these recent studies that the cloacal septum ever reaches the cloacal membrane $[8,9,11]$. Rather, the anal and urethral openings are formed by apoptosis of the cloacal membrane.

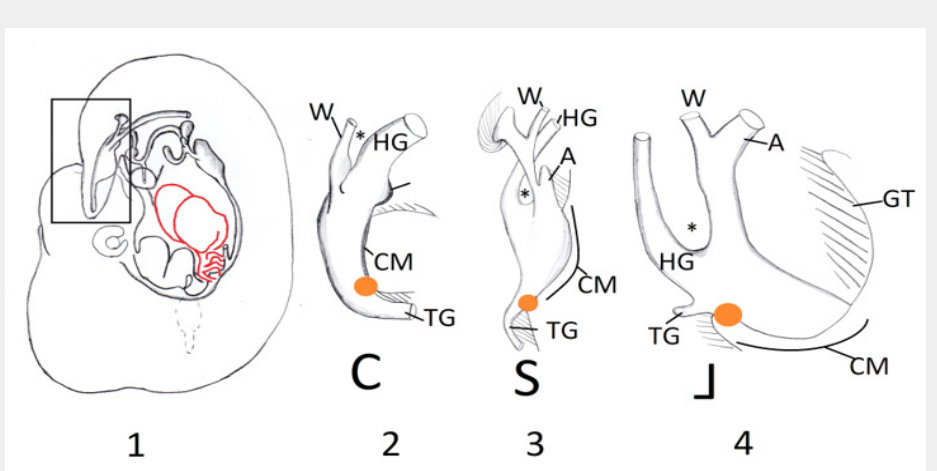

1.A murine embryo schematic of approx. $11 \frac{1}{2}$ days showing $\mathrm{Gl}$ tract for orientation, the boxed area is drawn in detail in further images. 2. Before reduction of the marked caudal folding the cloacal membrane (CM) is roughly vertical. The 'cloacal septum' $\left({ }^{*}\right)$ consists of only the gap between the Wolffian duct (W) and hindgut (HG). The tailgut forms the lower arc of a ' $\mathrm{C}$ ' formed together with the hindgut. The orange dot represents the fixed point of mesenchyme at the caudal part of the $\mathrm{CM}$. Dashed lines represent mesenchyme, being absent at the cloacal membrane.

3. As the caudal curve of the embryo is reduced the ventral aspect of the cloaca expands and the intercloacal septum is seen to extend caudally towards the fixed point of the mesenchyme at the caudal extreme of the cloacal membrane. This draws the tailgut into a sigmoidal shape. The allantois $(\mathrm{A})$ becomes evident.

4. The arrival of the mesenchyme of the genital tubercle draws the whole complex ventrally, pulling it away from the fixed point of the caudal cloacal membrane, developing the cloacal septum in the process and causing the tailgut to adopt an L-shaped relationship to the hindgut. Adapted from diagrams and data in [8-10,12]

Figure 1: The developmental stages of tail-gut regression and cloacal morphogenesis.

Of note, the mesenchyme at the caudal extreme of the cloaca (i.e. the cephalic extreme of the tailgut, dot in (Figure 1) seems to act as a fixed point around which the remainder of genitourinary structures are distorted by the relative growth of mesenchyme and caudal unfolding [9]. Embryonic unfolding creates a sigmoidal relationship between cloaca and tailgut. It is at approximately this point (Carnegie stage 14/15) that the tailgut typically receeds [10].

Were the tailgut to persist, an L like relationship would presumably be created between tailgut and hindgut as the genital tubercle distorts the cloaca with its marked outward growth [8,9]; causing the proximal part of any tailgut remnant to come to lie in the same horizontal plane as the cloacal membrane. This would explain how a tailgut remnant could be retained in the absence of a tail; how it comes to lie anteriorly to the sacrum but posteriorly to rectum; and why it is occasionally closely associated with the anal muscles. It also explains why the tailgut cysts are so often found embedded within the mesorectum.

\section{Conclusion}

Tailgut cysts are incredibly rare lesions. Outside of quaternary referral centres, a gastroenterologist counselling a patient is unlikely to have treated such a lesion before. There is an increasing volume of literature on their malignant threat but sparse description of if, or how, excision should be approached. This makes onward referral for surgical management problematic. The latest models of anorectal development [8-12] are able to provide an explanation for the position of tailgut cysts observed in the adult; though this has not been explicitly stated before. This explanation has as a weakness that it takes an a priori form, based on current sparse knowledge of anorectal morphogenesis and clinical descriptions of tailgut cysts. This flaw is in common with much of the anatomical theory supporting TME excision. Importantly, such an explanation allows for a rational approach to the oncologic resection of tailgut cysts, since their associated mesentery will be inseparable from that of the rectum. Similarly, lymphatics can be argued to trace to the inferior mesenteric pedicle and a prophylactic or curative excision can rationally be achieved by use of the TME plane.

\section{References}

1. Nicoll K, Bartrop C, Walsh S, Foster R, Duncan G, et al. (2019) Malignant Transformation of Tailgut Cysts is Significantly Higher than Previously Reported: Systematic Review of Cases in the Literature. Colorectal Dis 21(8): 869- 878.

2. Delibegovic S (2017) Introduction to Total Mesorectal Excision. Medical archives (Sarajevo, Bosnia and Herzegovina). 71(6): 434-438. 
3. Gutiérrez PC, Taghavi MK, Sosa RD, Angel Pelayo Salas, Victor Jacinto Ovejero, et al. (2014) New surgical approach of retrorectal cystic hamartoma using transanal minimally invasive surgery (TAMIS). Journal of Coloproctology (Rio de Janeiro) 34(4): 260-264.

4. Metzger R, Metzger U, Fiegel HC, Kluth D (2011) Embryology of the midgut. Semin Pediatr Surg 20(3): 145-151.

5. Kluth D, Jaeschke-Melli S, Fiegel H (2003) The embryology of gut rotation. Semin Pediatr Surg 12(4): 275- 279.

6. Retterer E (1890) Sur L'origin et de L'evolution de la Region Ano-gentiale des Mammiferes. J Anat Physiol 26: 126-210.

7. Tourneux F (1888) Sur les Premiers Dévelopements du Cloaque du Tubercule Génital et de L'anus Chez L'embryon de Mouton. Anat Physiol 24: 503-517.

This work is licensed under Creative Commons Attribution 4.0 License DOI:10.19080/ARGH.2020.15.555902
8. Holschneider AM (2006) Anorectal Malformations in Children: Embryology, Diagnosis, Surgical Treatment, Follow-up. ( $1^{\text {st }}$ edn) Springer-Verlag, Berlin, Heidelberg, Germany, p. 49- 63.

9. Huang YC, Chen F, Li X (2016) Clarification of mammalian cloacal morphogenesis using high-resolution episcopic microscopy. Dev Biol 409(1): 106-113.

10. Kruepunga N, Hikspoors JPJM, Mekonen HK, Mommen GMC, Meemon $\mathrm{K}$, et al. (2018) The development of the cloaca in the human embryo. J Anat 233(6): 724-739.

11. Qi BQ, Beasley SW, Williams AK, Fizelle F (2000) Apoptosis during regression of the tailgut and septation of the cloaca. J Pediatr Surg 35(11): 1556-1561.

12. Theiler K (1989) The House Mouse Atlas of Embryonic Development ( $1^{\text {st }}$ edn.), Springer-Verlag,London, England, p. 81- 85.

\section{Your next submission with JuniperPublishers will reach you the below assets}

- Quality Editorial service

- Swift Peer Review

- Reprints availability

- E-prints Service

- Manuscript Podcast for convenient understanding

- Global attainment for your research

- Manuscript accessibility in different formats

( Pdf, E-pub, Full Text, audio)

- Unceasing customer service

Track the below URL for one-step submission https://juniperpublishers.com/online-submission.php 